\title{
The expression of emotional skills among individual and team sports male athletes
}

\author{
Akelaitis A.V. ${ }^{1 \mathrm{ABCDE}}$, Malinauskas R.K. ${ }^{2 \mathrm{ABCDE}}$ \\ 1巴 ithuanian University of Educational Sciences, Lithuania \\ ${ }^{2}$ Department of Health, Physical and Social Education, Lithuanian Sports University, Lithuania
}

Authors' Contribution: A - Study design; B - Data collection; C - Statistical analysis; D - Manuscript Preparation; E - Funds Collection.

\begin{abstract}
Purpose:

Athlete must recognize and manage one's emotions, as well as their opponents and teammates emotions, in order to perform well in sports. For athletes, higher emotional skills have been linked to higher performance in sports.

Purpose: to reveal the peculiarities of the expression of emotional skills among individual and team sports male athletes.

Material: $\quad$ the participants comprised of 204 individual sports (track and field athletes, gymnasts, swimmers, badminton players, table tennis players, bodybuilders, and cyclists) and 212 team sports (basketball, football, volleyball, handball, and rugby players) male athletes from Lithuanian sport clubs/schools, age ranged 15 to 18 years old. The measures of emotional skills were evaluated using Social Emotional School Readiness Scale (BUSSESR), Rosenberg Self-Esteem Scale, and Emotional Intelligence Questionnaire - Short Form (TEIQue - SF). In order to analyse data, descriptive statistics (mean, standard deviation), Student's t test, and Cohen's d were utilized.

Results: $\quad$ the comparison of the expression of emotional skills among individual and team sports male athletes revealed that team sports male athletes have higher rate of self-awareness and self-regulation skills than individual sports male athletes $(p<.05)$. Meanwhile, Student's $t$ test for independent samples showed that there no significant differences between individual and team sports male athletes in terms of their abilities to express emotions, and self-esteem skills ( $p>.05)$.

Conclusions: the findings of the quantitative study confirmed our research hypothesis that male athletes who compete in team sports will have more developed emotional skills than those in individual sports: team sports male athletes have more developed self-awareness and self-regulation skills than individual sports male athletes.

Keywords: emotional skills, self-awareness, self-regulation, self-esteem, ability to express emotions, individual sports athletes, team sports athletes.
\end{abstract}

\section{Introduction}

In today's sport world, physical exercise is not regarded as the main factor to achieve success. Sport is an environment where individuals have to motivate themselves to achieve long-term goals through hard training. Athletes are required to consistently cope with the stress of hard training and competitive pressure, and this includes understanding and regulating their emotions and those of other individuals (e.g., opponents, teammates, coaches, referees, and spectators) [1, 2].

The researchers within the field of sport and exercise psychology have demonstrated that athletes scoring higher on emotional intelligence tests are more successful [3-5]. It was found that emotional intelligence relates to more successful athletic performance [6]; to physiological stress responses [7]; to psychological skill usage [8]; a greater occurrence of pleasant emotions [9]; a lower reported intensity of anxiety (an unpleasant emotion) before a competition [10]; a greater athletic success motivation (the ability to motivate oneself efficiently toward sport achievement) [11]; to a more frequent use of self-talk, imagery, emotional control, goal setting, activation, and relaxation techniques in practice and competition [8]. Skills such as relaxation, imagery, mindfulness, energy (c) Akelaitis A.V., Malinauskas R.K., 2018 doi:10.15561/18189172.2018.0201 control, reframing, and goal setting have all been found to play an important role in athletes' performance across a variety of individual and team sports [12]. According to D. Singh and colleagues, athletes with higher emotional intelligence are able to pay attention to the worries and concerns of others, can listen to someone without the urge to say something, can stay focused under pressure, are able to handle multiple demands and able to identify and separate their emotions [13]. S. Laborde and colleagues indicated that athletes with higher emotional intelligence might perform better because they appraise competitions as a challenge and use more effective coping strategies in response to competition stress [5].

In the past two decades, the concept of emotional intelligence-popularized by D. Goleman [14]-has gained a great deal of attention and popularity among different disciplines, largely because of its potential to influence human performance, relationships, and well-being [15]. Emotional intelligence refers to individual responses to intrapersonal or interpersonal emotional information and encompasses the identification, expression, understanding and regulation of personal or others' emotions [16, 17].

Overall, research in sport settings has provided evidence that emotional skills facilitate athletic performance with both team and individual athletes [1]. 
For individual sports athletes, is very important to be able to recognize their own optimal performance states especially under stressful and pressure situations. In order to achieve their individual zone of functioning, they need to develop skills to manage their emotions and control their energy levels [18]. Team sports demand athletes in a group to communicate, collaborate, and work as a unit towards common goals. As such, it is important to be mindful and aware of the other players' thoughts and emotions in order to react appropriately to a given situation [19]. According to N. Stambulova [20], individual sports athletes are more independent, more introverted, have more individual goals, and competition between the individual athletes is more common. These athletes have the possibility to control different situations, for example, trainings and competitions and they have higher responsibility over the results. Team sports athletes goals are both individual and team goals and they also have less control over sport when situations because one athlete can't determine the outcome of trainings or competitions, it's a result of the whole teams effort [20]. P. Totterdell [21] noted that teammates can influence another player's emotional state, e.g., one player's mistake may place another player in a situation where he could fail. Indeed, interactions with others can reduce a player's control of a situation [22].

After the theoretical substantiation of the assumptions for the emotional skills of individual and team sports male athletes it appeared that the following emotional skills components are most important to the emotional development of athletes: self-awareness, self-regulation, self-esteem, and ability to express emotions.

Self-awareness - the ability to accurately recognize one's own emotions, thoughts, and values and how they influence behaviour. The ability to accurately assess one's strengths and limitations, with a well-grounded sense of confidence, optimism, and a "growth mindset" [23].

Self-regulation - the ability to successfully regulate one's emotions, thoughts, and behaviours in different situations - effectively managing stress, controlling impulses, and motivating oneself. The ability to set and work toward personal and academic goals [23].

Self-esteem - is totality of the individual's thoughts and feelings with reference to himself as an object [24].

Ability to express emotions - the ability to express emotions in one's and other people physical states, feelings, and thoughts [25].

Taking into account these things, a hypothesis is raised in the work that those who compete in team sports will have more developed emotional skills than those in individual sports. This expectation builds upon the assumption that team sports provide athletes more opportunities to interact (e.g., communicate, collaborate) with others, and that helps support athlete's social and emotional development $[1,26]$.

The purpose of the research - to reveal the peculiarities of the expression of emotional skills among individual and team sports male athletes.

\section{Material and methods}

Participants:

When the population size is known, the following formula is used to determine the sample size [27]:

$$
\mathrm{n}=\frac{\mathrm{N} \cdot 1.96^{2} \cdot \mathrm{p} \cdot \mathrm{q}}{\varepsilon^{2} \cdot(\mathrm{N}-1)+1,96^{2} \cdot \mathrm{p} \cdot \mathrm{q}}
$$

$\mathrm{N}$ - the population size; the value 1.96 corresponds to $95 \%$ confidence level of the standard normal distribution; $\mathrm{p}$ is the predicted result probability that the analysed attribute will be evident in the surveyed population (usually, the worst scenario probability - the attribute is typical for the half of the population, i.e. $50 \%$ - is taken and then $\mathrm{p}=0.5$ ); $\mathrm{q}$ is the probability that the analysed attribute will not be evident in the surveyed population $(\mathrm{q}=1-\mathrm{p}=0.5) ; \varepsilon$ is the required accuracy, usually $\varepsilon$ $=0.05$. Whereas the population size male athletes is approximately $\mathrm{N}=5,000$ persons, hence, the sample size calculated according to this formula is $n=357$. Therefore, it can be stated that the sample of 357 respondents is a representative one.

Participants of this study include 416 male athletes, aged between 15 and 18 years $(M=16.42, S D=1.63)$, who are member of one of the sport clubs/schools and regularly participate in team practice at least three sessions per week and in the last year have been place on the competition conditions. The study employed a random (probability) sampling method, i.e., the athletes (15-18 years old) from Lithuanian sport clubs/schools should have equal opportunities to be included into the sample. Researchers selected 204 athletes of individual sports including: track and field $(\mathrm{n}=79)$, gymnastics $(\mathrm{n}=21)$, swimming $(\mathrm{n}=24)$, badminton $(\mathrm{n}=27)$, cycling $(\mathrm{n}=12)$, body building $(\mathrm{n}=9)$, table tennis $(\mathrm{n}=32)$, and 212 athletes of team sports including: basketball $(\mathrm{n}=87)$, football $(\mathrm{n}=51)$, volleyball $(\mathrm{n}=30)$, handball $(\mathrm{n}=25)$, and rugby $(\mathrm{n}=19)$ from Kaunas, Vilnius, Klaipeda, Siauliai, Panevezys, and Alytus cities sport clubs/schools.

\section{Instruments:}

To determine emotional skills of individual and team sports male athletes, we used following questionnaires:

Social Emotional School Readiness Scale (BUSSESR), developed by C. Bustin [28]. The questionnaire was developed for assessment of students' self-awareness, self-regulation, social relationships, empathy, and coping skills. The BUSSE-SR comprises 50 statements (in our case 25 statements). In this study, we used only the selfawareness (11 statements, e.g., „I can tell others what I would like to do") and self-regulation (14 statements, e.g., „I am able to wait turn to speak in a group”) skills assigned parts of the questionnaire. Answering to each statement, the respondents had to choose the variants of their answer by using a 4 - point Likert rating scale with the following categories: „Never"; „Sometimes“; „Mostly“, and „Always“. In the current study a Cronbach alpha of .89 was found for the BUSSE-SR total score (self-awareness subscale -.88 , self-regulation subscale - 
.87), indicating high internal reliability.

The Rosenberg Self-Esteem Scale (RSES) [24] is widely used in social science research and is a global measure of self-esteem. It consists of 10 items to which responses are given using a four-point Likert scale ranging from 1 - „strongly disagree“ to 4 - „strongly agree“. The Lithuanian version of the RSES has a reported internal consistency of .73 [29]. In the current study a Cronbach's alpha of .72 was found for the RSES total score, indicating acceptable internal reliability.

Emotional Intelligence Questionnaire - Short Form (TEIQue - SF), developed by K.V. Petrides and A. Furnham [17]. The TEIQue-SF consists of 15 subscales (including ability to express emotions), organized under four factors: well-being, self-control, emotionality, and sociability. The questionnaire consists of 30 items (two items from each of the 15 subscales). Participants indicate their responses on a 7 - point Likert scale, ranging from 1 - „completely disagree“, to 7 - „completely agree“. High scores on ability to express emotions subscale mean people are fluent in communicating their emotions to others, they know what the best words are for expressing their feelings accurately and unambiguously. Low scores on this subscale indicate a difficulty in communicating emotion related thoughts, even in situations when this is necessary. People with low scores find it difficult to let others know how they feel [30]. In the current study a Cronbach alpha coefficient for the TEIQue - SF total score was .84 (ability to express emotions subscale - .89).

Procedures:

The quantitative study was carried out during the period from March, 2017 to May, 2017. The authors were present during the meetings with the athletes and informed them about the study and related ethical issues. The athletes were informed that the obtained data would be used for scientific goals only and provided in a general way in order not to identify any concrete persons. The data of these persons chosen for the statistical analysis of results complied with all the requirements for the research because the principles of the voluntary basis and anonymity were observed. The permission was obtained from sport clubs/schools administrators to conduct the study. Prior to collecting data from the minor athletes, parental informed consent forms were completed. The duration of the survey was 20 minutes.

Statistical analysis:

The statistical research data analysis was performed by using the SPSS (Statistical Package for Social Sciences, version 22.0) programme package. Descriptive statistics, means $(M)$ and standard deviation $(S D)$ were calculated for each of the items of the tests. We calculated the reliability of each dimension given by the index of Cronbach alpha internal consistence. Student's $t$ test for independent samples was chosen for the evaluation of statistical significance between two groups: individual sports group and team sports group. Effect sizes for mean differences were expressed as Cohen's $d$, which are generally defined as follows: small $(d=.2)$, medium $(d=$ $.5)$, and large $(d=.8)$. Statistical significance was set at $p<.05$.

\section{Results}

The goal of the research was to identify and compare the results of the expression of emotional skills among individual and team sports male athletes. Student's $t$ test for independed samples showed that team sports male athletes have more developed self-awareness skills than individual sports male athletes: $(t(414)=-1.99$; $p<.05$; $d=.20)$. The analysis of self-awareness skills resulted in the following averages: individual sports male athletes - $30.24 \pm 2.09$, and team sports male athletes - 30.66 \pm 2.21 . The comparison of the expression of emotional skills among individual and team sports male athletes also revealed that team sports male athletes $(39.97 \pm 4.94)$ have higher rate of self-regulation skills than individual sports $(39.03 \pm 4.79)$ male athletes: $(t(414)=-1.97 ; p$ $<.05 ; \mathrm{d}=.19)$. The obtained results are summarized in Table 1.

Table 1. The statistical indicators of emotional skills among individual and team sports male athletes $(n=416)$

\begin{tabular}{|c|c|c|c|c|c|c|}
\hline Emotional skills & Sport & $\mathbf{N}$ & $\mathbf{M}$ & SD & $\begin{array}{l}\text { Scores of } \\
\text { Student's } t \text { - test }\end{array}$ & Cohen's d \\
\hline \multirow{2}{*}{ Self-awareness } & Individual & 204 & 30.24 & 2.09 & \multirow{2}{*}{$-1.99 *$} & \multirow{2}{*}{.20} \\
\hline & Team & 212 & 30.66 & 2.21 & & \\
\hline \multirow{3}{*}{ Self-esteem } & Individual & 204 & 17.08 & 2.46 & \multirow{3}{*}{-.77} & \multirow{3}{*}{.08} \\
\hline & & & & & & \\
\hline & Team & 212 & 17.26 & 2.33 & & \\
\hline \multirow[b]{2}{*}{ Self-regulation } & Individual & 204 & 39.03 & 4.79 & \multirow[b]{2}{*}{$-1.97^{*}$} & \multirow[b]{2}{*}{.19} \\
\hline & Team & 212 & 39.97 & 4.94 & & \\
\hline \multirow[b]{2}{*}{ Ability to express emotions } & Individual & 204 & 9.14 & 2.69 & \multirow[b]{2}{*}{-1.20} & \multirow[b]{2}{*}{.12} \\
\hline & Team & 212 & 9.45 & 2.57 & & \\
\hline
\end{tabular}

Note: $\mathrm{N}$ - number of participants; M - mean; SD - standard deviation; Cohen's $d$ - effect size; ${ }^{*}-p<.05$. 
Meanwhile, Student's $t$ test for independent samples showed that there no significant differences between individual and team sports male athletes in terms of their abilities to express emotions, and self-esteem skills ( $p$ > $.05)$.

\section{Discussion}

The main purpose of this study was to reveal the peculiarities of the expression of emotional skills among individual and team sports male athletes. The findings of the quantitative study confirmed our research hypothesis that those who compete in team sports will have more developed emotional skills than those in individual sports. It was found that team sports male athletes have higher rate of self-awareness (a small effect, $d=.20$ ) and selfregulation (a small effect, $d=.19$ ) skills than individual sports male athletes. G.H. Soflu, N. Esfahani and H. Assadi also observed that there are some differences in emotional intelligence between individual and team sports athletes [31]. Authors found, that there is a significant difference between self-management, self-motivation, and social skills between these two groups, but no significant difference was observed in self-awareness and empathy micro scales. K.R. Singh and A. Mili [32] compared emotional intelligence between individual sports, dual sports and team sports athletes. The following research indicated that team sport athletes have higher selfregulation, motivation, and total emotional intelligence score than individual sports athletes. Dual sports athletes who are played by two people striving against one another (e.g., tennis and racquetball) - have higher rate of selfregulation, motivation, and social skills, and performed better on total emotional intelligence than individual sports athletes [32]. C. Calmels in a similar research stated that team sports athletes compared to individual sports athletes possessing better communicative skills and have more ability in motivating their teammates but individual sports athletes experience higher levels of selftalk and negative thinking [33]. N. Stambulova evaluated that team sports athletes have a closer relationship to their teammates and the athletes experiences more stress over; fear of making mistakes, conflict between their individual goals and the team goals, higher fear of injuries and conflicts in the team [20]. It has also been shown that team sport athletes have higher self-referenced competency, affiliation with peers, competitive excitement, positive parental involvement and enjoyment compared with individual sport athletes [34].

In contrast, several studies compared emotional skills between team sports and individual sports athletes and found no observable differences [5, 11, 35], but there may be several explanations for this finding. First, previous researches have been related to compare emotional skills between athletes with different levels (e.g., beginner, amateur, sub elite, elite, and non-athletes). According to the earlier research findings carried out by S. Laborde, F. Dosseville, and M.S. Allen [1]; Madzar T. et al. [36]; Znazen H. et al. [37], elite players (professional athletes) apply different types of mental skills in order to control their competitive anxiety; they have higher selfconfidence and positive effect on emotions regulation. Second, a subject of previous researches consists of both male and female athletes. S. Laborde, F. Dosseville, and M.S. Allen found that male athletes had higher levels of trait emotional intelligence than female athletes [1]. G.H. Soflu, N. Esfahani, and H. Assadi observed that female athletes have more negative thinking and lower relaxation than male athletes [31]. In contrast, Dunn and colleagues found that women score higher than men on one particular dimension of emotional intelligence - emotion management [38]. Third, this can be interpreted as the emotional skills being equally important in individual and team sports. In general, conducting the research in order to compare emotional skills between team sports and individual sports athletes, the homogeneity of groups should be ensured.

There were several methodological limitations of this study. First, the current study analyses only $15-18$ years old athletes' peculiarities of the expression of emotional skills, although further study is worth to analyse older athletes' emotional skills as well and compare data of these age groups athletes. Research suggests that older adults may obtain higher emotional skills due to increased experience [39], lifelong learning, and accumulating knowledge [40]. Another limitation is that we selected athletes from different types of team sports, e.g., contact team sports, such as basketball or football, are distinctly different from collision sports (e.g., rugby), not only in their rules, but also in the potential emotional experiences elicited through the direct and intense physicality involved in these sports [41].

\section{Conclusions}

The present study revealed the expression of emotional skills among individual and team sports male athletes. The results of this study indicate that the significant difference exists in emotional skills among individual sports and team sports male athletes: team sports male athletes have more developed self-awareness and have higher rate of self-regulation skills than individual sports male athletes.

According to the other components of emotional skills (ability to express emotions and self-esteem) between individual sports and team sports male athletes statistically significant difference was not observed.

\section{Conflict of interests:}

The authors declare that there is no conflict of interests. 


\section{References:}

1. Laborde S, Dosseville F, Allen MS. Emotional intelligence in sport and exercise: A systematic review. Scandinavian Journal of Medicine \& Science in Sports, 2015; 26(8): 862874. doi:10.1111/sms.12510

2. Korobeynikov G, Korobeinikova L, Shatskih V. Age, PsychoEmotional States and Stress Resistance in Elite Wrestlers. International Journal of Wrestling Science, 2013;3:58-69. doi:10.1080/21615667.2013.10878970

3. Crombie D, Lombard C, Noakes TD. Emotional intelligence scores predict team sports performance in a national cricket competition. International Journal of Sports Science \& Coaching, 2009; 4: 209-224.

4. Jones MV. Emotion regulation and sport performance. The Oxford handbook of sport and performance psychology. NewYork, NY: Oxford University Press; 2012.

5. Laborde S, Dosseville F, Guillén F, Chávez E. Validity of the trait emotional intelligence questionnaire in sports and its links with performance satisfaction. Psychology of Sport and Exercise, 2014; 15: 481-490.

6. Laborde S, Lautenbach F, Allen MS, Herbert C, Achtzehn S. The role of trait emotional intelligence in emotion regulation and performance under pressure. Personality and Individual Differences, 2014; 57: 43-47.

7. Laborde S, Raab M, Kinrade NP. Is the ability to keep your mind sharp under pressure reflected in your heart? Evidence for the neurophysiological bases of decision reinvestment. Biological Psychology, 2014; 100: 34-42.

8. Lane AM, Thelwell RC, Lowther J, Devonport TJ. Emotional intelligence and psychological skills use among athletes. Social Behavior and Personality, 2009; 37: 195-202.

9. Lane AM, Wilson MR. Emotions and trait emotional intelligence among ultra-endurance runners. Journal of Science and Medicine in Sport, 2011; 14: 358-362.

10.Lu FJ, Li GS, Hsu EY, Williams L. Relationship between athletes' emotional intelligence and precompetitive anxiety. Perceptual and Motor Skills, 2010; 110: 323-338.

11.Kajbafnezhad H, Ahadi H, Heidarie A, Askari P, Enayati M. Predicting athletic success motivation using mental skills and emotional intelligence and its components in male athletes. Journal of sports medicine and physical fitness, 2012; 52: 551-557.

12.Crust L, Azadi K. Mental toughness and athletes' use of psychological strategies. European Journal of Sport Science, 2010; 10(1): 43-51. doi:10.1080/17461390903049972

13.Dalwinder Singh, Simerjeet Kaur, Gaurav Dureja. Emotional maturity differentials among university students. Journal of Physical Education and Sports Management, 2012;3(3):4145. doi:10.5897/JPESM11.076

14.Goleman D. Emotional intelligence. New York, NY; England: Bantam Books, Inc, 1995.

15.Stough C, Saklofske DH, Parker JDA. Assessing emotional intelligence: theory, research, and applications. New York, NY: Springer Science; 2009.

16. Mayer JD, Salovey P. What is emotional intelligence? In: Salovey P, Sluyter D, eds. Emotional development and emotional intelligence: educational implications. NewYork: Basic Books; 1997.

17.Petrides KV, Furnham, A. The role of trait emotional intelligence in a gender-specific model of organizational variables. Journal of Applied Social Psychology, 2006; 36: 552-569.

18.Hanin YL. Individual zones of optimal functioning (IZOF) model: An idiographic approach to performance anxiety. In Henschen K, Straub W (Eds.), Sport psychology: An analysis of athlete behavior Longmeadow, MA: Movement Publications; 1995. P.103-119.

19.Abraham R. Emotional intelligence in organizations: A conceptualization. Genetic, Social, and General Psychology Monographs [serial on the Internet], 1999 [cited 2018 Feb 2]; 125(2): 209-224. Available from: https://login. lib-proxy.usi.edu/login?url=http://search.proquest.com/ docview/231513130? accountid=14752

20.Stambulova N. Applied psychological work in individual \& team sports. Unpublished lecture handout. Halmstad University; 2006.

21.Totterdell P. Catching moods and hitting runs: Mood linkage and subjective performance in professional sport teams. The Journal of Applied Psychology, 2000; 85: 848-859.

22.Mann DTY, Williams AM, Ward P, Janelle CM. Perceptualcognitive expertise in sport: A meta-analysis. Journal of Sport \& Exercise Psychology, 2007; 29: 457-478.

23.Collaborative for Academic, Social, and Emotional Learning (CASEL). Core SEL competencies [document on the Internet]. Chicago: Author, 2017 (April) [cited 2018 Feb 8]. Available from: http://www.casel.org/core-competencies/

24.Rosenberg M. Society and The Adolescent Self-Image. Princeton, NJ: Princeton University Press; 1989.

25. Mayer JD, Salovey P, Caruso DR, Cherkasskiy L. Emotional intelligence. In Sternberg RJ, Kaufman SB (Eds.), The Cambridge handbook of intelligence New York, NY: Cambridge University Press; 2011. P. 528-549).

26.Durlak J, Weissberg R, Dymnicki A, Taylor R, Schellinger K. The Impact of Enhancing Students' Social and Emotional Learning: A MetaAnalysis of School-Based Universal Interventions. Child Development, 2011; 82(1): 405-432.

27.Schwarce J. Grundlagen der Statistik 2. 5th edition. Berlin: Neue Wirtschaftsbriefe; 1993.

28.Bustin C. The development and validation of social emotional school readiness scale. University of the Free State; 2007.

29.Malinauskas R, Klizas Š, Šniras Š. Social adjustment among students of middle school age during physical education lessons. Education. Physical Training. Sport. 2008; 2(69):52-56. (in Lithuanian)

30.Petrides KV, Furnham A. Trait emotional intelligence: Psychometric investigation with reference to established trait taxonomies. European Journal of Personality, 2001; 15: 425-448.

31.Soflu GH, Esfahani N, Assadi H. The Comparison of emotional intelligence and psychological skills and their relationship with experience among individual and Team athletes in superior league. Social and Behavioral Sciences, 2011; 30: 2394-2400.

32.Singh KR, Mili A. Study of Emotional Intelligence among Players of Individual, Dual and Team Sports. International Journal of Science and Research, 2015; 12(5): 1101-1106.

33.Calmels C. Development of mental skills among athletes. Expert use in Elite Sport - INSEP. 2002.

34.McCarthy PJ, Jones M, Carter DC. Understanding enjoyment in youth sport: A developmental perspective. Psychology of Sport and Exercise, 2008; 9(2): 142-156.

35.Batinic TS, Svaic V, Babic J. Differences in emotional competence between individual and team sports athletes. Proceedings of the 7th international scientific conference on kinesiology: fundamental and applied kinesiology - steps forward, 2014 May 22 - 25; Opatija. University of Zagreb, Faculty of Kinesiology Zagreb, Croatia; 2014. P. 552-555.

36. Madzar T, Milosevic M, Hrabac P, Heningsberg N. Psychological aspects of sports injuries among male professional soccer players in Croatia. Kinesiology. 2017;49(1):84-91. 
37.Znazen H, Slimani M, Miarka B, Butovskaya M, Siala H, Messaoud T, et al. Mental skills comparison between elite sprint and endurance track and field runners according to their genetic polymorphism: a pilot study. Journal of Sports Medicine and Physical Fitness. 2017;57(9):1217-1226. doi:10.23736/s0022-4707.16.06441-0

38.Dunn EW, Brackett MA, Ashton-James C, Schneiderman E, Salovey P. On emotionally intelligent time travel: individual differences in affective forecasting ability. Personality \& Social Psychology Bulletin, 2007; 33: 85-93.
39.Goleman D. Working with emotional intelligence. New York, NY; England: Bantam Books, Inc; 1998.

40.Sliter M, Chen YW, Withrow S, Sliter K. Older and (emotionally) smarter? Emotional intelligence as a mediator in the relationship between age and emotional labor strategies in service employees. Experimental Aging Research, 2013; 39(4): 466-479. doi: 10.1080/0361073X.2013.808105

41.Maxwell JP, Visek AJ, Moores E. Anger and perceived legitimacy of aggression in male Hong Kong Chinese athletes: Effect of type of sport and level of competition. Psychology of Sport and Exercise, 2009; 10: 289-296.

\section{Information about the authors:}

Akelaitis A.V.; Dr.; http://orcid.org/0000-0001-9643-9402; arturas.akelaitis@leu.lt; Lithuanian University of Educational Sciences; 39 Studentų St., Vilnius LT-08106, Lithuania.

Malinauskas R.K. (Corresponding author); Professor, Dr.; http://orcid.org/0000-0001-5578-3100; romas.malinauskas@lsu.lt; Department of Health, Physical and Social Education, Lithuanian Sports University; Sporto 6, 44221 Kaunas, Lithuania

Cite this article as: Akelaitis AV, Malinauskas RK. The expression of emotional skills among individual and team sports male athletes. Pedagogics, psychology, medical-biological problems of physical training and sports, 2018;22(2):62-67. doi:10.15561/18189172.2018.0201

The electronic version of this article is the complete one and can be found online at: http://www.sportpedagogy.org.ua/index.php/PPS/issue/archive

This is an Open Access article distributed under the terms of the Creative Commons Attribution License, which permits unrestricted use, distribution, and reproduction in any medium, provided the original work is properly cited (http://creativecommons.org/licenses/by/4.0/deed.en).

Received: 05.12.2017

Accepted: 18.01.2018; Published: 30.04.2018 